\title{
Robotic prostatectomy and access to care: Canadian vs. U.S. experience
}

\author{
Kevin C. Zorn, MD, FACS, FRCSC; Marc Zanaty, MD; ${ }^{-1}$ Assaad El-Hakim, MD, FRCSC ${ }^{1}$
}

'Université de Montréal Hospital Centre (CHUM), Montreal, QC, Canada

Cite as: Can Urol Assoc J 2016;10(5-6):202-3. http://dx.doi.org/10.5489/cuaj.3846

See related article on page 192.

$\mathrm{T}$ he field of urology has witnessed tremendous changes in surgical practice over the past few decades. Infusion of novel technology and minimally invasive instrumentation have been extensively evaluated and embraced into the urological community with a primal, ongoing desire to improve patient outcome. Since the pioneering laparoscopic work by Schuessler et al in 1992, ${ }^{1}$ it was not until 1998 that Dr. Guillonneau at the Institut Mutualiste Montsouris perfected laparoscopic radical prostatectomy (LRP). ${ }^{2}$ While LRP was adopted quickly in Europe, the lack of technical expertise and ergonomic challenges dampened its application in North America. For such reasons, the advent of robotic-assisted surgical systems in 2000, with benefits of magnified three-dimensional imaging, full-range motion surgical arms, articulating instruments with 7 degrees of freedom, and safer surgeon ergonomics helped foster the enthusiasm of minimally invasive treatments for localized prostate cancer (PCa), most significantly in the U.S. ${ }^{3}$

The authors of the current article, "Robotic prostatectomy is associated with increased patient travel and treatment delay," have highlighted this rapid uptake of robotic technology in their retrospective review of the National Cancer database with the increase in robotic RP from $<10 \%$ in 2004-2005 to over $70 \%$ by $2010-2011 .{ }^{4}$ Comprehensive analysis of data also demonstrates that men undergoing RARP were associated with increased travel distances ( $>25$ miles) and treatment delay ( $>90$ days). Unfortunately, no pathological or followup data were available to assess the impact of such features on disease-specific survival or biochemical recurrence. In other words, we are unable to draw conclusions on whether longer delay to surgery correlates with worse oncological outcomes. Alternatively, do men who receive treatment faster or closer to home have better outcomes?

While initial reaction may suggest unfavourable patient outcomes, closer review of the data suggests more region- alization and centralization of RARP at high-volume, comprehensive academic centres. As we know, there is now ample evidence favouring improved outcomes, reduced complications, reduced overall health charges, ${ }^{5-7}$ reduced positive surgical margins, ${ }^{8}$ and improved early continence outcomes $^{9}$ for high-volume surgeons.

The concept of surgical delay is an important concern for both physicians and patients, particularly for oncological surgery. The surgeon is, on one hand, concerned that the delay affects prognosis; the patient, is equally disturbed by the stress and anticipation of the waiting period. While psychological factors should not be taken lightly, there is no well-established evidence that the increased time to surgery impacts the outcome in localized PCa. In the current study, it is noteworthy to point out that $>70 \%$ of men undergoing RARP in 2010-2011 were operated within $<90$ days, with $<4 \%$ having a surgical delay $>180$ days. Unfortunately, the definition of delay is not clear in the manuscript and may be assumed to be the time from biopsy to surgery. Multiple factors, including time to obtain final pathology report, time to obtain imaging (computed tomography [CT], magnetic resonance imaging [MRI], bone scan) and multiple consultations must be considered in this simple calculation. There is also data to support waiting four weeks prior to prostate MRI to improve pathological accuracy. ${ }^{10,11}$ Similarly, Martin et al have demonstrated that RARP within six weeks of biopsy was associated with a greater risk of complications even when controlling for disease and patient characteristics. ${ }^{12}$ Unfortunately, these are not addressed in the present study. Furthermore, it is important to highlight the fact that men in their study who underwent RARP were $27 \%$ less likely to be of high-risk cancer on multivariate analysis $(p<0.001)$. While the current report does not focus on the details of those men who were waiting $>3$ months, there are several reports that increasing durations of RP delay beyond 5-9 months in low-risk cancer is not associated with pathological upstaging and PCa mortality. ${ }^{13}$ Other studies have reported that wait time does not affect pathological outcomes or biochemical recurrence. ${ }^{14-16}$ Moreover, increased wait times have been observed to have adverse effects on intermediate-risk disease 
only, with a threshold of more than 3-9 months. ${ }^{17,18}$ As such, it appears that RARP surgery in the U.S. as of 2010-2011 is being performed within an appropriate timeframe. ${ }^{19}$

We feel that his study is meaningful insofar that it highlights not only the rapid uptake of RARP in the U.S. over a relatively short time period, but confirms the socioeconomic and racial disparities in the surgical care of localized $\mathrm{PCa} .{ }^{20}$ Additionally, we can appreciate the trend of ongoing centralization of complex cancer surgery at high-volume, academic centres invested in robotic technology.

From a Canadian perspective, this study also is interesting since it draws attention to the limited access to RARP. Aside from restricted access to operative time, availability of robotic technology in a socialized healthcare system is limited. Unlike the U.S., where most hospital centres purchase the robot, all daVinici systems in Canada have been acquired through donor-funded, foundation-purchased systems. As such, cost-related features of the robot significantly limit the implementation in Canadian hospitals. Moreover, when compared to Canada with a population of 35.7 million and 25 daVinici installed systems, the U.S. (population of 318.9 million and access to 2344 daVinci robots), has a 10.5 -fold access advantage to such technology. Thus, the extrapolation to greater travel distances and operative wait time to Canadian patients would intuitively be higher.

Unlike comparable countries, surgical wait times in Canada appear to be increasing and are well beyond the threshold recommended by national and international expert bodies. ${ }^{21}$ Even though the association between surgical delay and disease recurrence remains unclear, there is an ongoing concern that the psychological impact of prolonged waiting could negatively impact patient outcomes. To address these important issues, a similar Canadian study with risk stratification should be undertaken addressing the impact of surgical wait time on adverse pathological outcomes and biochemical recurrence - particularly for RARP.

Competing interests: Dr. Zorn is a consultant and an Advisory Board member for Boston Scientific. The remaining authors declare no competing personal or financial interests.

\section{References}

1. Schuessler WW, Schulam PG, Clayman RV, et al. Laparoscopic radical prostatectomy: Initial short-term experience. Urology 1997;50:854-7. http://dx.doi.org/10.1016/S0090-4295(97)00543-8

2. Guillonneau B, Cathelineau X, Barret E, et al. Laparoscopic radical prostatectomy: Technical and early oncological assessment of 40 operations. Eur Urol 1999;36:14-20. http://dx.doi.org/10.1159/000019921
3. Skarecky DW. Robotic-assisted radical prostatectomy after the first decade: Surgical evolution or new paradigm. ISRN Urol 2013;2013:157379. http://dx.doi.org/10.1155/2013/157379

4. Maurice MJ, Zhu H, Kim SP, et al. Robotic prostatectomy is associated with increased patient travel and treatment delay. Can Urol Assoc J 2016;10:192-201. http://dx.doi.org/10.5489/cuaj.3628

5. Leow JJ, Reese $S$, Trinh QD, et al. Impact of surgeon volume on the morbidity and costs of radical cystectomy in the USA: A contemporary population-based analysis. BJU Int 2015;115:713-21. http:// dx.doi.org/10.1111/bju.12749

6. Abdollah F, Budäus L, Sun M, et al. Impact of caseload on total hospital charges: A direct comparison between minimally invasive and open radical prostatectomy — a population based study. J Urol 2011;185:855-61. htrp://dx.doi.org/10.1016/i.juro.2010.10.051

7. Trinh QD, Sammon J, Sun M, et al. Perioperative outcomes of robot-assisted radical prostatectomy compared with open radical prostatectomy: Results from the Nationwide Inpatient Sample. Eur Urol 2012;61:679-85. http://dx.doi.org/10.1016/j.eururo.2011.12.027

8. Hu JC, Gandaglia G, Karakiewicz PI, et al. Comparative effectiveness of robot-assisted versus open radical prostatectomy cancer control. Eur Urol 2014;66:666-72. http://dx.doi.org/10.1016/i. eururo.2014.02.015

9. Ficarra V, Novara G, Rosen RC, et al. Systematic review and meta-analysis of studies reporting urinary continence recovery after robot-assisted radical prostatectomy. Eur Urol 2012;62:405-17. http://dx.doi. org/10.1016/i.eururo.2012.05.045

10. Ikonen S, Kivisaari L, Vehmas T, et al. Optimal timing of post-biopsy MR imaging of the prostate. Acto Radiol 2001;42:70-3. http://dx.doi.org/10.1034/i.1600-0455.2001.042001070.x

11. Ko YK, Song PH, Moon KH, et al. Asian J Androl 2014;16: 280-4. http://dx.doi.org/10.4103/1008$682 X .122190$

12. Martin GL, Nunez RN, Humphreys MD, et al. Interval from prostate biopsy to robot-assisted radical prostatectomy: Effects on perioperative outcomes. BJU Int 2009;104:1734-7. http://dx.doi.org/10.1111/ j.1464-410X.2009.08685.x

13. Sun $\mathrm{M}$, Abdollah $\mathrm{F}$, Hansen J, et al. Is a treatment delay in radical prostatectomy safe in individuals with low-risk prostate cancer? J Sex Med 2012;9:2961-9. http://dx.doi.org/10.1111/j.17436109.2012.02806.x

14. Vickers AJ, Bianco FJ, Boorijan $\mathrm{S}$, et al. Does a delay between diagnosis and radical prostatectomy increase the risk of disease recurrence? Cancer 2006;106:576-80. http://dx.doi.org/10.1002/cncr.21643

15. Korets $R$, Seager $C M$, Pitman MS, et al. Effect of delaying surgery on radical prostatectomy outcomes: A contemporary analysis. BJU Int 2012;110:211-6. http://dx.doi.org/10.1111/i.1464410X.2011.10666.X

16. Khan MA, Mangold LA, Epstein Jl, et al. Impact of surgical delay on long-term cancer control for clinically localized prostate cancer. J Urol 2004;172:1835-9. http://dx.doi.org/10.1097/01. ju.0000140277.08623.13

17. O'Brien D, Loeb S, Carvalhal GF, et al. Delay of surgery in men with low-risk prostate cancer. J Urol 2011;185:2143-7. http://dx.doi.org/10.1016/i.juro.2011.02.009

18. Abern MR, Aronson WJ, Terris MK, et al. Delayed radical prostatectomy for intermediate-risk prostate cancer is associated with biochemical recurrence: Possible implications for active surveillance from the SEARCH database. The Prostate 2013;73:409-17. http://dx.doi.org/10.1002/pros.22582

19. Berg WT, Danzig MR, Pak JS, et al. Delay from biopsy to radical prostatectomy influences the rate of adverse pathologic outcomes. Prostate 2015;75:1085-91. http://dx.doi.org/10.1002/pros.22992

20. Schmid $M$, Meyer $C P$, Reznor $G$, et al. Racial differences in the surgical care of medicare beneficiaries with localized prostate cancer. JAMA Oncol 2016;2:85-93. http://dx.doi.org/10.1001/jamaoncol.2015.3384

21. Saad F, Finelli A, Dranitsaris G, et al for the Canadian surgical wait times (SWAT) initiative. Does prolonging the time to prostate cancer surgery impact long-term cancer control: A systematic review of the literature. Can J Urol 2006; 13:16-24.

Correspondence: Dr. Kevin Zorn, Université de Montréal Hospital Centre (CHUM), Montreal, QC, Canada; zorn.chumurology@gmail.com 